Review

\title{
Human Papillomavirus and Tonsillar and Base of Tongue Cancer
}

\author{
Torbjörn Ramqvist, Nathalie Grün and Tina Dalianis * \\ Department of Oncology-Pathology, Karolinska Institutet, Cancer Center Karolinska R8:01, \\ Karolinska University Hospital, 17176 Stockholm, Sweden; \\ E-Mails: Torbjorn.Ramqvist@ki.se (T.R.); Nathalie.Grun@ki.se (N.G.) \\ * Author to whom correspondence should be addressed; E-Mail: Tina.Dalianis@ki.se; \\ Tel.: +46-8-51776583.
}

Academic Editor: Joanna Parish

Received: 13 February 2015 / Accepted: 17 March 2015 / Published: 20 March 2015

\begin{abstract}
In 2007, human papillomavirus (HPV) type 16 was recognized as a risk factor by the International Agency for Research on Cancer, for oropharyngeal squamous cell carcinoma (OSCC), where tonsillar and base of tongue cancer (TSCC and BOTSCC) dominate. Furthermore, patients with HPV-positive TSCC and BOTSCC, had a much better clinical outcome than those with corresponding HPV-negative cancer and other head and neck cancer. More specifically, survival was around 80\% for HPV-positive TSCC and BOTSCC vs. 40\% five-year disease free survival, for the corresponding HPV-negative tumors with conventional radiotherapy and surgery, while this could not be observed for HPV-positive OSCC at other sites. In addition, the past 20-40 years in many Western Countries, the incidence of HPV-positive TSCC and BOTSCC has risen, and $>70 \%$ are men. This has resulted in a relative increase of patients with HPV-positive TSCC and BOTSCC that may not need the intensified chemo-radiotherapy (with many more severe debilitating side effects) often given today to patients with head and neck cancer. However, before tapering therapy, one needs to enable selection of patients for such treatment, by identifying clinical and molecular markers that together with HPV-positive status will better predict patient prognosis and response to therapy. To conclude, there is a new increasing group of patients with HPV-positive TSCC and BOTSCC with good clinical outcome, where options for better-tailored therapy are needed. For prevention, it would be of benefit to vaccinate both girls and boys against HPV16 infection. For potential future screening the ways to do so need optimizing.
\end{abstract}


Keywords: human papillomavirus; tonsillar squamous cell carcinoma; base of tongue squamous cell carcinoma cancer; clinical outcome; oral HPV prevalence

\section{Introduction}

Twenty years ago in 1995, the International Agency for Research against Cancer acknowledged an association between human papillomavirus (HPV) type 16 and cancer of the cervix, uteri, and other anogenital cancer [1]. It took another 12 years for HPV16 to be recognized as a risk factor for oropharyngeal squamous cell carcinoma (OSCC) in 2007, dominated tonsillar and base of tongue cancer (TSCC and BOTSCC) and where HPV is mainly found [2-7]. The most notable difference between HPV-positive TSCC and BOTSCC compared to their HPV-negative counterparts and other head and neck squamous cell carcinoma (HNSCC) is the better clinical outcome ( $80 \%$ vs. $40 \%$ five-year disease specific survival) [2-4,6-9]. This difference in clinical outcome has not been observed between HPV-positive and HPV-negative OSCC at other sites other than TSCC and BOTSCC [6]. In the past decades, the incidence of especially TSCC and BOTSCC (and thereby also OSCC) has increased in many Western countries, mainly due to a rise of HPV-positive TSCC and BOTSCC cases and $>70 \%$ are men [8,10-21]. HNSCC has poor prognosis in general and is now given more aggressive treatment with more intensified chemotherapy and radiotherapy, leading to more adverse side effects [21]. Such therapy may not be beneficial for most patients with HPV-positive TSCC and BOTSCC, where $80 \%$ of the patients survived, before treatment was intensified, and when given only conventional radiotherapy alone, with the addition of surgery if needed [2-4,6-9,19]. Here, differences between HPV-positive and HPV-negative TSCC and BOTSCC and issues of finding biomarkers in HPV-positive TSCC and BOTSCC useful for predicting which patients may have a good response to therapy and be eligible for de-escalated therapy trials are described. Data on oral HPV infection, effects of HPV vaccination, and potential screening for TSCC and BOTSCC are also discussed.

\section{Human Papillomavirus (HPV) and Disease and Cancer}

There are $>170$ HPV types, with the majority found in the skin (cutaneous HPV types), but many also found in mucous tissues (mucosal HPV types) and where clearly the vast majority cause only asymptomatic infections [22,23]. A phylogenetic tree based on the homologous nucleotide sequence of the major capsid protein L1 groups the different HPV types into five genera - alpha, beta, gamma, mu and nu [23]. The mucosal types are included in genera alpha and the others mainly consist of cutaneous types [23].

Mucosal HPV types can be divided into high-risk (HR) types that have a clear and well-recognized potential to cause cancer, or low-risk types (LR) that are very rarely observed in cancer [22,23]. The best-known association between HR-HPVs and cancer is that of HPV and cancer of the uterine cervix [22]. However, HPV is also associated with vulvar, vaginal, penile and anal cancer, and since 2007, HPV16 has also been acknowledged to be a risk factor for OSCC, where tonsillar and base of tongue cancer dominate [5,22-25]. Furthermore, in addition to HPV16, HPV33, HPV35 and others (also found in cervical cancer) have been observed to contribute to OSCC [4,7,15,24,26]. LR-HPV types 
are not associated with cancer development in general, but are often found in benign genital lesions, such as condylomas and recurrent respiratory papillomas [22,23].

Cutaneous HPV types are best known to cause skin warts, but multiple skin cancers may emerge from verruca-like papillomatous lesions in Epidermodyplasia vercucciformis (EV) patients that are especially sensitive to infections with e.g., HPV5 and 8 [1,5,23]. Whether HPV is responsible for other squamous cell carcinoma of the skin is however still a question of debate.

HPVs have double stranded circular DNA genomes of around $7.9 \mathrm{~kb}$. The genome, including a non-coding control region (NCCR), an early and a late coding region, is enclosed together with histones within a $52-55 \mathrm{~nm}$ virion $[23,24]$. The regulatory proteins E1-E2, E4-E7 important for gene regulation, replication and pathogenesis are coded by the early region, while the two structural proteins L1 and L2 responsible for the viral capsid are encoded by the late region [23,24]. E6 and E7 regarded as oncogenes in HR-HPV types and have high affinity to $\mathrm{p} 53$ and pRb, respectively, and are without doubt of relevance for immortalization and transformation [23,24]. The binding of E6 to p53 causes its degradation, preventing e.g., control of DNA damage and cell repair or apoptosis, while the binding of $\mathrm{E} 7$ to $\mathrm{Rb}$ and abrogates deregulation of cell cycle control $[1,18,19,23,24]$. The latter, also results in an increase in the expression of the cyclin dependent kinase inhibitor $\mathrm{p} 16^{\mathrm{INK} 4 \mathrm{a}}[23,27]$. Overexpression of $\mathrm{p} 16^{\mathrm{INK} 4 \mathrm{a}}$ was in the past used as a surrogate marker for presence of HPV in OSCC [24,27]. Today, neither overexpression of p16 ${ }^{\mathrm{INK} 4 \mathrm{a}}$ or the presence of HPV DNA alone, are regarded as sufficient to point that a tumor is caused by HPV [24,28]. However, presence of HPV DNA combined with $\mathrm{p} 16^{\mathrm{INK} 4 \mathrm{a}}$ overexpression is almost as sensitive as using the golden standard, i.e. analyzing for presence of HPV E6 and E7 mRNA [24,28]. The L1 major capsid protein contributes to around $80 \%$ of the viral capsid and can spontaneously self-assemble into virus-like particles (VLPs) under specific conditions [22,23,29]. Todays' HPV vaccines Cevarix (GMK) and Gardasil (Merk) consist of VLPs from different HPV types and both contain HPV16 and 18 VLPs, while the latter also contains VLPs also of HPV6 and HPV11 [30,31]. These vaccines have been shown to be very efficient against cervical HPV infection, and also very likely efficient against oral HPV infection [30-35].

\section{TSCC, BOTSCC and HPV and Its Influence on Clinical Outcome and Number of Cases}

OSCC includes not only TSCC and BOTSCC, which accounting for $80 \%$ of the cases, but also cancer of the walls of the pharynx and the soft palate [36]. However, it becomes evident that the presence of HPV is highest in TSCC and BOTSCC (79\% and 73\%, respectively), which both contain lymphoid tissue and together contribute to Waldeyers ring, while in other OSCC the presence of HPV is lower $(17 \%)[6,8,17]$. This is not always appreciated, and it is likely that this distinction must also be made more clearly before selecting patients for clinical studies. Furthermore, HPV16 is present in $>90 \%$ of the HPV-positive TSCC and BOTSCC cases, and even more common than in cervical cancer, where HPV16 accounts for $50 \%-55 \%$ of the cases; moreover, most of the patients are men [1-7,23,24,26]. Taken together, this is also of importance when reflecting over HPV vaccination against these tumors.

The most prominent difference between HPV-positive and HPV-negative TSCC and BOTSCC is that patients with HPV-positive tumors have a much better clinical outcome than those with HPV-negative tumors and other head and neck cancer, including OSCC other than TSCC and BOTSCC $(80 \%$ vs. $40 \%$ five-year survival) [3,4,7-9]. In the literature, similar findings with regard to clinical outcome are 
found for HPV-positive and HPV-negative OSCC, which is not surprising, since the numbers of OSCC cases outside the tonsil and base of tongue at other subsites are limited and do not change the general trend $[4,6,36]$.

Patients with HPV-positive TSCC and BOTSCC as compared to those with HPV-negative tumors are also often somewhat younger, more often non-smokers, have smaller tumors, but have a higher tumor stage, since many patients also have nodal disease [2-4,6-9,37]. Nonetheless, the latter still does not necessarily affect the better survival among patients in the HPV-positive group [2-4,6-9,37].

Most HPV-positive TSCC and BOTSCC independent of episomal/and or integrated HPV genomes, exhibit E6 and E7 mRNA expression; with p53 expression more often, being normal and with $16^{\text {Ink4a }}$ overexpressed in most cases, in contrast to that observed in HPV-negative TSCC and OSCC [23,37-40]. HPV-positive TSCC and BOTSCC is also generally less differentiated; more frequently aneuploid compared to HPV-negative OSCC; and chromosome 3q often amplified similar to cervical cancer, but amplification of chromosome $3 \mathrm{q}$ did not further influence clinical outcome [41,42]. HPV has repeatedly been a favorable prognostic marker, independent of tumor stage, age, gender, differentiation, or DNA ploidy, and in never-smokers clinical outcome has generally been found to be even better [2-4,6-9,37,41,42].

Today the golden standard of HPV-positive status in TSCC/BOTSCC/OSCC is the presence of E6 and E7 mRNA expression by RT-PCR, suggested to be associated with functional HPV expression [28]. Notably, the combined presence of HPV DNA tested by PCR and p16 overexpression is now more and more widely recognized as very close to the golden standard in TSCC and BOTSCC and especially useful for analysis in formalin fixed paraffin embedded (FFPE) tumor samples [28]. Nonetheless, in the past many ways of defining HPV-positive status have been used, including different types of PCR assays and primers, which may have given some variations in the results obtained. [4,7,27,28,37,43-48]. Moreover, HPV prevalence varies not only due to the methodology used, but also depending on geographical location and time period of investigation. Numerous studies have indicated an increase in HPV prevalence in TSCC, BOTSCC and OSCC the past decades and this has certainly contributed to the increased incidence of these tumors that has been reported from many Western countries [8,10-21].

For example, between 1970 and 2002, a three-fold increase in both the incidence and prevalence of HPV (both in women and men) was observed in TSCC in Stockholm, Sweden and this lead to the hypothesis that HPV was responsible for the increase in incidence of TSCC [15]. This was followed by additional reports again from Stockholm, showing that HPV-positive TSCC had increased with a seven-fold doubling per decade 1970-2007, while HPV-negative cancer had decreased and analogous changes were also reported for BOTSCC $[8,14,17]$. The most recent report from Sweden, shows a continued increase in incidence of TSCC and BOTSCC, however, while the number of HPV-positive TSCC cases remains high in the Stockholm area, it has not increased the past five years [49]. Whether this trend is temporary or not needs to be investigated further.

Parallel to the Stockholm studies, an emerging epidemic of HPV associated OSCC was suggested in the US, and in 2011 in the U.S. a rise in the incidence of HPV-positive OSCC and a decline in HPV-negative OPCC was also reported for the past decades [11,12,16,21]. Furthermore, during the same period accumulating reports from many Western countries, such as Scotland, the UK, and the Netherlands, conveyed an increasing incidence of OSCC, while in Eastern Denmark an increase in HPV-positive TSCC was described $[10,13,20,50]$. 
As already mentioned, the increase in incidence of TSCC, BOTSCC and OSCC has been suggested due to a rise in HPV-positive cases and changes in life style, and there is a significant correlation between HPV-positive OSCC, early sex debut, and numbers of oral or vaginal partners [51]. However, it has also been shown that oral-to-oral contact and HPV-transmission at birth may also result in oral HPV infection [52,53]. Clearly, in many Western countries, the numbers of HPV-positive TSCC and BOTSCC, where most patients are men, are still increasing, although new trends may be appearing $[8,10-21,49,50]$.

\section{TSCC, BOTSCC, HPV and Other Biomarkers and Treatment}

HPV-positive TSCC and BOTSCC contribute to an increasing proportion of HNSCC in recent years [19]. Furthermore, this group of patients with a favorable clinical outcome already with conventional radiotherapy, may in most cases not need the intensified chemo-radiotherapy, with more side effects and increasing expenses for society that is given to head- and neck-cancer today [19,24]. Thus, it is imperative to distinguish patients that need intensive therapy from those who do not. For this purpose, it is important to combine positive HPV-status with additional biomarkers in order to better predict response to therapy and only select patients with a very probable good response rate to randomized trials with lessened therapy.

It has been shown that for TSCC and BOTSCC, the presence of HPV DNA/RNA and p16 overexpression are very good prognostic markers especially when combined with accurate data on that the patient being a never smoker [9,28,37]. In fact even the quantity of smoking, i.e., package years, was also important [37]. However, none of these factors distinguish $100 \%$ of the patients and additional markers are therefore needed.

Additional biomarkers have been investigated. It has been reported that absent/low expression of MHC class I, CD44, CD98, LMP7, or LMP10 intensity staining, or absence of HLA-A*02, or high LRIG1 expression improved prediction of clinical outcome for patients with HPV-positive TSCC and BOTSCC [54-62]. Absence of HLA class I immunohistochemistry (IHC) staining, e.g., indicated a 95\%-100\% probability of a three-year disease free survival, but identified only around $20 \%$ of the patients with a good clinical outcome [56,57]. In addition, the high CD8+ tumor infiltrating lymphocyte (TIL) counts were also very favorable for patients with HPV-positive TSCC and BOTSCC as compared to the corresponding tumors with low CD8+ TIL counts, but was less sensitive $[63,64]$.

That having high CD8+ TIL counts was favorable was expected, since an efficient immune response may result in a favorable clinical outcome of HPV-positive TSCC and BOTSCC [63,64]. More enigmatic was that HPV-positive TSCC and BOTSCC with absent HLA class I expression had good prognosis since HLA class I down-regulation abrogates the immune response, especially in absence of NK-cells [56,57]. Here, it is possible that HPV E5 and E7 expression contributes to HLA class I downregulation and that treatment increases HLA class I expression this way enhancing the immune response against these tumors [56,57].

Other biomarkers that have been investigated are miRNAs and data are accumulating, but stringent concordance between different studies has not been shown so far [65-67]. 
Clearly, additional molecular knowledge and ways to combine different markers, both clinical and molecular for prediction of clinical outcome in patients with HPV-positive TSCC and BOTSCC would be of great value.

\section{Prevention of HPV-Positive TSCC and BOTSCC}

HPV16 is the most common HPV type in the oral cavity in non-vaccinated individuals [68-71]. Oral HPV prevalence, including all HPV types, varies and has been reported to be $3 \%-9 \%$ in studies including individuals at all ages and when limited to unvaccinated youth [68-71]. Furthermore, it has been shown that women with a cervical HPV infection more often have an oral HPV infection [68].

In HPV vaccinated groups, oral HPV prevalence, especially HPV16, seems to be lower than in non-vaccinated groups suggesting a vaccination effect [32-35]. Thus vaccinating both girls and boys against HPV16 may be a good option not only to prevent cervical cancer but also to prevent the majority of HPV16 positive TSCC and BOTSCC in the future, especially since $>70 \%$ of the latter comprise men.

For non-vaccinated individuals, other approaches may be of interest and screening may not be optimal for several reasons especially since the incidence of HPV-positive TSCC and BOTSCC is still relatively low $[12,14,49]$. Furthermore, testing HPV-prevalence in the oral cavity could result in an underestimation, e.g., due to saliva production, and some individuals may be reported as falsely negative because the obtained HPV signals are generally lower compared to those obtained for the cervical site [68].

Nevertheless, in the proportion of patients with HPV-positive TSCC and BOTSCC, it has been shown that the viral load of HPV16 in mouthwashes is considerably higher than that obtained in healthy youth and often comparable to that obtained in the cervix [72]. Whether a high viral HPV load is indicative of HPV-positive TSCC and BOTSCC needs to be investigated further. However, there is also the possibility to combine this approach with serology, where certain antibody profiles, especially the appearance of HPV16 E6 have been shown to predict risk for development of HPV-positive OSCC, and such antibodies are very seldom found in non-cancer patients $[73,74]$. Alternatively, serology could be used to identify patients at risk for OSCC and these patients could be followed using mouthwashes [72,73]. Using cytology has also been attempted, but not found very useful so far [67,75].

\section{Conclusions}

HPV-positive TSCC and BOTSCC have better clinical outcome than corresponding HPV-negative cancers and are increasing in incidence. Preventing spread of HPV16 infection by vaccination, and deescalating intensive therapy by using additional predictive markers to identify and select HPV-positive TSCC and BOTSCC patients eligible for randomized trials with lessened therapy are issues of importance.

\section{Acknowledgments}

This work was supported in part by the Swedish Cancer Foundation, the Stockholm Cancer Society, the Cancer and Allergy Foundation, the Stockholm City Council and the Karolinska Institutet, Sweden. 


\section{Author Contributions}

TD wrote the review. TR read and modified the review and completed the reference list. NG read and modified the review.

\section{Conflicts of Interest}

The authors declare no conflict of interest.

\section{References}

1. IARC. Human Papillomaviruses; WHO: Lyon, France, 1995; Volume 64.

2. Dahlgren, L.; Dahlstrand, H.M.; Lindquist, D.; Hogmo, A.; Bjornestal, L.; Lindholm, J.; Lundberg, B.; Dalianis, T.; Munck-Wikland, E. Human papillomavirus is more common in base of tongue than in mobile tongue cancer and is a favorable prognostic factor in base of tongue cancer patients. Int. J. Cancer 2004, 112, 1015-1019.

3. Dahlstrand, H.M.; Dalianis, T. Presence and influence of human papillomaviruses (HPV) in tonsillar cancer. Adv. Cancer Res. 2005, 93, 59-89.

4. Gillison, M.L.; Koch, W.M.; Capone, R.B.; Spafford, M.; Westra, W.H.; Wu, L.; Zahurak, M.L.; Daniel, R.W.; Viglione, M.; Symer, D.E.; et al. Evidence for a causal association between human papillomavirus and a subset of head and neck cancers. J. Natl. Cancer Inst. 2000, 92, 709-720.

5. IARC. Human Papillomaviruses; WHO: Lyon, France, 2007; Volume 90.

6. Marklund, L.; Näsman, A.; Ramqvist, T.; Dalianis, T.; Munck-Wikland, E.; Hammarstedt, L. Prevalence of human papillomavirus and survival in oropharyngeal cancer other than tonsil or base of tongue cancer. Cancer Med. 2012, 1, 82-88.

7. Mellin, H.; Friesland, S.; Lewensohn, R.; Dalianis, T.; Munck-Wikland, E. Human papillomavirus (HPV) DNA in tonsillar cancer: Clinical correlates, risk of relapse, and survival. Int. J. Cancer 2000, 89, 300-304.

8. Attner, P.; Du, J.; Nasman, A.; Hammarstedt, L.; Ramqvist, T.; Lindholm, J.; Marklund, L.; Dalianis, T.; Munck-Wikland, E. The role of human papillomavirus in the increased incidence of base of tongue cancer. Int. J. Cancer 2010, 126, 2879-2884.

9. Lindquist, D.; Romanitan, M.; Hammarstedt, L.; Nasman, A.; Dahlstrand, H.; Lindholm, J.; Onelov, L.; Ramqvist, T.; Ye, W.; Munck-Wikland, E.; et al. Human papillomavirus is a favourable prognostic factor in tonsillar cancer and its oncogenic role is supported by the expression of e 6 and e7. Mol. Oncol. 2007, 1, 350-355.

10. Braakhuis, B.J.; Visser, O.; Leemans, C.R. Oral and oropharyngeal cancer in the netherlands between 1989 and 2006: Increasing incidence, but not in young adults. Oral. Oncol. 2009, 45, e85-e89.

11. Chaturvedi, A.K.; Engels, E.A.; Anderson, W.F.; Gillison, M.L. Incidence trends for human papillomavirus-related and -unrelated oral squamous cell carcinomas in the united states. J. Clin. Oncol. 2008, 26, 612-619. 
12. Chaturvedi, A.K.; Engels, E.A.; Pfeiffer, R.M.; Hernandez, B.Y.; Xiao, W.; Kim, E.; Jiang, B.; Goodman, M.T.; Sibug-Saber, M.; Cozen, W.; et al. Human papillomavirus and rising oropharyngeal cancer incidence in the united states. J. Clin. Oncol. 2011, 29, 4294-4301.

13. Conway, D.I.; Stockton, D.L.; Warnakulasuriya, K.A.; Ogden, G.; Macpherson, L.M. Incidence of oral and oropharyngeal cancer in united kingdom (1990-1999)—Recent trends and regional variation. Oral. Oncol. 2006, 42, 586-592.

14. Hammarstedt, L.; Dahlstrand, H.; Lindquist, D.; Onelov, L.; Ryott, M.; Luo, J.; Dalianis, T.; Ye, W.; Munck-Wikland, E. The incidence of tonsillar cancer in sweden is increasing. Acta Otolaryngol. 2007, 127, 988-992.

15. Hammarstedt, L.; Lindquist, D.; Dahlstrand, H.; Romanitan, M.; Dahlgren, L.O.; Joneberg, J.; Creson, N.; Lindholm, J.; Ye, W.; Dalianis, T.; et al. Human papillomavirus as a risk factor for the increase in incidence of tonsillar cancer. Int. J. Cancer 2006, 119, 2620-2623.

16. Marur, S.; D’Souza, G.; Westra, W.H.; Forastiere, A.A. HPV-associated head and neck cancer: A virus-related cancer epidemic. Lancet Oncol. 2010, 11, 781-789.

17. Nasman, A.; Attner, P.; Hammarstedt, L.; Du, J.; Eriksson, M.; Giraud, G.; Ahrlund-Richter, S.; Marklund, L.; Romanitan, M.; Lindquist, D.; et al. Incidence of human papillomavirus (HPV) positive tonsillar carcinoma in stockholm, sweden: An epidemic of viral-induced carcinoma? Int. J. Cancer 2009, 124, 150-156.

18. Ramqvist, T.; Dalianis, T. Oropharyngeal cancer epidemic and human papillomavirus. Emerg. Infect. Dis. 2010, 16, 1671-1677.

19. Ramqvist, T.; Dalianis, T. An epidemic of oropharyngeal squamous cell carcinoma (oscc) due to human papillomavirus (HPV) infection and aspects of treatment and prevention. Anticancer Res. 2011, 31, 1515-1519.

20. Robinson, K.L.; Macfarlane, G.J. Oropharyngeal cancer incidence and mortality in scotland: Are rates still increasing? Oral. Oncol. 2003, 39, 31-36.

21. Sturgis, E.M.; Cinciripini, P.M. Trends in head and neck cancer incidence in relation to smoking prevalence: An emerging epidemic of human papillomavirus-associated cancers? Cancer 2007, 110, 1429-1435.

22. Tommasino, M. The human papillomavirus family and its role in carcinogenesis. Semin. Cancer Biol. 2014, 26, 13-21.

23. Zur Hausen, H. Papillomavirus infections: A major cause of human cancer. In Infections Causing Human Cancer; Wiley-VCH Verlag: Weinheim, Germary, 2006; pp. 145-243.

24. Dalianis, T. Human papillomavirus and oropharyngeal cancer, the epidemics, and significance of additional clinical biomarkers for prediction of response to therapy (review). Int. J. Oncol. 2014, 44, 1799-1805.

25. IARC. Human papillomaviruses. In Iarc Monographs on the Evaluation of Carcinogenic Risk to Humans. A Review of Human Carcinogens. B. Biological Agents; WHO: Lyon, France, 2011; Volume 100B, pp. 261-301.

26. Du, J.; Nasman, A.; Carlson, J.W.; Ramqvist, T.; Dalianis, T. Prevalence of human papillomavirus (HPV) types in cervical cancer 2003-2008 in stockholm, sweden, before public HPV vaccination. Acta Oncol. 2011, 50, 1215-1219. 
27. Oguejiofor, K.K.; Hall, J.S.; Mani, N.; Douglas, C.; Slevin, N.J.; Homer, J.; Hall, G.; West, C.M. The prognostic significance of the biomarker p16 in oropharyngeal squamous cell carcinoma. Clin. Oncol. 2013, 25, 630-638.

28. Smeets, S.J.; Hesselink, A.T.; Speel, E.J.; Haesevoets, A.; Snijders, P.J.; Pawlita, M.; Meijer, C.J.; Braakhuis, B.J.; Leemans, C.R.; Brakenhoff, R.H. A novel algorithm for reliable detection of human papillomavirus in paraffin embedded head and neck cancer specimen. Int. J. Cancer 2007, 121, 2465-2472.

29. Ramqvist, T.; Andreasson, K.; Dalianis, T. Vaccination, immune and gene therapy based on virus-like particles against viral infections and cancer. Expert Opin. Biol. Ther. 2007, 7, 997-1007.

30. Group, F.I.S. Quadrivalent vaccine against human papillomavirus to prevent high-grade cervical lesions. N. Engl. J. Med. 2007, 356, 1915-1927.

31. Paavonen, J.; Jenkins, D.; Bosch, F.X.; Naud, P.; Salmeron, J.; Wheeler, C.M.; Chow, S.N.; Apter, D.L.; Kitchener, H.C.; Castellsague, X.; et al. Efficacy of a prophylactic adjuvanted bivalent 11 virus-like-particle vaccine against infection with human papillomavirus types 16 and 18 in young women: An interim analysis of a phase iii double-blind, randomised controlled trial. Lancet 2007, 369, 2161-2170.

32. Grun, N.; Ahrlund-Richter, A.; Franzen, J.; Mirzaie, L.; Marions, L.; Ramqvist, T.; Dalianis, T. Oral human papillomavirus (HPV) prevalence in youth and cervical HPV prevalence in women attending a youth clinic in sweden, a follow up-study 2013-2014 after gradual introduction of public HPV vaccination. Infect. Dis. 2015, 47, 57-61.

33. Herrero, R.; Quint, W.; Hildesheim, A.; Gonzalez, P.; Struijk, L.; Katki, H.A.; Porras, C.; Schiffman, M.; Rodriguez, A.C.; Solomon, D.; et al. Reduced prevalence of oral human papillomavirus (HPV) 4 years after bivalent HPV vaccination in a randomized clinical trial in costa rica. PLOS ONE 2013, 8, e68329.

34. Antonsson, A.; Cornford, M.; Perry, S.; Davis, M.; Dunne, M.P.; Whiteman, D.C. Prevalence and risk factors for oral HPV infection in young australians. PLOS ONE 2014, 9, e91761.

35. Nordfors, C.; Grun, N.; Haeggblom, L.; Tertipis, N.; Sivars, L.; Mattebo, M.; Larsson, M.; Haggstrom-Nordin, E.; Tyden, T.; Ramqvist, T.; et al. Oral human papillomavirus prevalence in high school students of one municipality in sweden. Scand. J. Infect. Dis. 2013, 45, 878-881.

36. Licitra, L.; Bernier, J.; Grandi, C.; Merlano, M.; Bruzzi, P.; Lefebvre, J.L. Cancer of the oropharynx. Crit. Rev. Oncol. Hematol. 2002, 41, 107-122.

37. Ang, K.K.; Harris, J.; Wheeler, R.; Weber, R.; Rosenthal, D.I.; Nguyen-Tan, P.F.; Westra, W.H.; Chung, C.H.; Jordan, R.C.; Lu, C.; et al. Human papillomavirus and survival of patients with oropharyngeal cancer. N. Engl. J. Med. 2010, 363, 24-35.

38. Koskinen, W.J.; Chen, R.W.; Leivo, I.; Makitie, A.; Back, L.; Kontio, R.; Suuronen, R.; Lindqvist, C.; Auvinen, E.; Molijn, A.; et al. Prevalence and physical status of human papillomavirus in squamous cell carcinomas of the head and neck. Int. J. Cancer 2003, 107, 401-406.

39. Mellin Dahlstrand, H.; Lindquist, D.; Bjornestal, L.; Ohlsson, A.; Dalianis, T.; Munck-Wikland, E.; Elmberger, G. P16(ink4a) correlates to human papillomavirus presence, response to radiotherapy and clinical outcome in tonsillar carcinoma. Anticancer Res. 2005, 25, 4375-4383. 
40. Mellin, H.; Dahlgren, L.; Munck-Wikland, E.; Lindholm, J.; Rabbani, H.; Kalantari, M.; Dalianis, T. Human papillomavirus type 16 is episomal and a high viral load may be correlated to better prognosis in tonsillar cancer. Int. J. Cancer 2002, 102, 152-158.

41. Dahlgren, L.; Mellin, H.; Wangsa, D.; Heselmeyer-Haddad, K.; Bjornestal, L.; Lindholm, J.; Munck-Wikland, E.; Auer, G.; Ried, T.; Dalianis, T. Comparative genomic hybridization analysis of tonsillar cancer reveals a different pattern of genomic imbalances in human papillomavirus-positive and -negative tumors. Int. J. Cancer 2003, 107, 244-249.

42. Mellin, H.; Friesland, S.; Auer, G.; Dalianis, T.; Munck-Wikland, E. Human papillomavirus and DNA ploidy in tonsillar cancer-Correlation to prognosis. Anticancer Res. 2003, 23, 2821-2828.

43. Clavel, C.; Masure, M.; Bory, J.P.; Putaud, I.; Mangeonjean, C.; Lorenzato, M.; Gabriel, R.; Quereux, C.; Birembaut, P. Hybrid capture II-based human papillomavirus detection, a sensitive test to detect in routine high-grade cervical lesions: A preliminary study on 1518 women. Br. J. Cancer 1999, 80, 1306-1311.

44. de Roda Husman, A.M.; Walboomers, J.M.; van den Brule, A.J.; Meijer, C.J.; Snijders, P.J. The use of general primers gp5 and gp6 elongated at their 3' ends with adjacent highly conserved sequences improves human papillomavirus detection by PCR. J. Gen. Virol. 1995, 76, 1057-1062.

45. Gravitt, P.E.; Peyton, C.L.; Apple, R.J.; Wheeler, C.M. Genotyping of 27 human papillomavirus types by using L1 consensus PCR products by a single-hybridization, reverse line blot detection method. J. Clin. Microbiol. 1998, 36, 3020-3027.

46. Schmitt, M.; Bravo, I.G.; Snijders, P.J.; Gissmann, L.; Pawlita, M.; Waterboer, T. Bead-based multiplex genotyping of human papillomaviruses. J. Clin. Microbiol. 2006, 44, 504-512.

47. Tieben, L.M.; ter Schegget, J.; Minnaar, R.P.; Bouwes Bavinck, J.N.; Berkhout, R.J.; Vermeer, B.J.; Jebbink, M.F.; Smits, H.L. Detection of cutaneous and genital HPV types in clinical samples by PCR using consensus primers. J. Virol. Methods 1993, 42, 265-279.

48. van den Brule, A.J.; Pol, R.; Fransen-Daalmeijer, N.; Schouls, L.M.; Meijer, C.J.; Snijders, P.J. Gp5+/6+ per followed by reverse line blot analysis enables rapid and high-throughput identification of human papillomavirus genotypes. J. Clin. Microbiol. 2002, 40, 779-787.

49. Nasman, A.; Nordfors, C.; Holzhauser, S.; Vlastos, A.; Tertipis, N.; Hammar, U.; Hammarstedt-Nordenvall, L.; Marklund, L.; Munck-Wikland, E.; Ramqvist, T.; et al. Incidence of human papillomavirus positive tonsillar and base of tongue carcinoma: A stabilisation of an epidemic of viral induced carcinoma? Eur. J. Cancer 2015, 51, 55-61.

50. Garnaes, E.; Kiss, K.; Andersen, L.; Therkildsen, M.H.; Franzmann, M.B.; Filtenborg-Barnkob, B.; Hoegdall, E.; Krenk, L.; Josiassen, M.; Lajer, C.B.; et al. A high and increasing HPV prevalence in tonsillar cancers in eastern denmark, 2000-2010: The largest registry-based study to date. Int. J. Cancer 2014, 136, 2196-2203.

51. Anaya-Saavedra, G.; Ramirez-Amador, V.; Irigoyen-Camacho, M.E.; Garcia-Cuellar, C.M.; Guido-Jimenez, M.; Mendez-Martinez, R.; Garcia-Carranca, A. High association of human papillomavirus infection with oral cancer: A case-control study. Arch. Med. Res. 2008, 39, 189-197.

52. D’Souza, G.; Agrawal, Y.; Halpern, J.; Bodison, S.; Gillison, M.L. Oral sexual behaviors associated with prevalent oral human papillomavirus infection. J. Infect. Dis. 2009, 199, 1263-1269. 
53. Syrjanen, S.; Puranen, M. Human papillomavirus infections in children: The potential role of maternal transmission. Crit. Rev. Oral Biol. Med. 2000, 11, 259-274.

54. Lindquist, D.; Ahrlund-Richter, A.; Tarjan, M.; Tot, T.; Dalianis, T. Intense CD44 expression is a negative prognostic factor in tonsillar and base of tongue cancer. Anticancer Res. 2012, 32, $153-161$.

55. Lindquist, D.; Nasman, A.; Tarjan, M.; Henriksson, R.; Tot, T.; Dalianis, T.; Hedman, H. Expression of LRIG1 is associated with good prognosis and human papillomavirus status in oropharyngeal cancer. Br. J. Cancer 2014, 110, 1793-1800.

56. Nasman, A.; Andersson, E.; Marklund, L.; Tertipis, N.; Hammarstedt-Nordenvall, L.; Attner, P.; Nyberg, T.; Masucci, G.V.; Munck-Wikland, E.; Ramqvist, T.; et al. HLA class I and II expression in oropharyngeal squamous cell carcinoma in relation to tumor HPV status and clinical outcome. PLOS ONE 2013, 8, e77025.

57. Nasman, A.; Andersson, E.; Nordfors, C.; Grun, N.; Johansson, H.; Munck-Wikland, E.; Massucci, G.; Dalianis, T.; Ramqvist, T. MHC class I expression in HPV positive and negative tonsillar squamous cell carcinoma in correlation to clinical outcome. Int. J. Cancer 2013, 132, $72-81$.

58. Nasman, A.; Nordfors, C.; Grun, N.; Munck-Wikland, E.; Ramqvist, T.; Marklund, L.; Lindquist, D.; Dalianis, T. Absent/weak CD44 intensity and positive human papillomavirus (HPV) status in oropharyngeal squamous cell carcinoma indicates a very high survival. Cancer Med. 2013, 2, 507-518.

59. Rietbergen, M.M.; Martens-de Kemp, S.R.; Bloemena, E.; Witte, B.I.; Brink, A.; Baatenburg de Jong, R.J.; Leemans, C.R.; Braakhuis, B.J.; Brakenhoff, R.H. Cancer stem cell enrichment marker CD98: A prognostic factor for survival in patients with human papillomavirus-positive oropharyngeal cancer. Eur. J. Cancer 2014, 50, 765-773.

60. Tertipis, N.; Haeggblom, L.; Grün, N.; Nordfors, C.; Näsman, A.; Dalianis, T.; Ramqvist, T. Reduced expression of the antigen processing machinery components TAP2, LMP2 and LMP7 in tonsillar and base of tongue cancer and implications for clinical outcome. Transl. Oncol. 2015, 8, $10-17$.

61. Tertipis, N.; Haeggblom, L.; Nordfors, C.; Grun, N.; Nasman, A.; Vlastos, A.; Dalianis, T.; Ramqvist, T. Correlation of $1 \mathrm{mp} 10$ expression and clinical outcome in human papillomavirus (HPV) positive and HPV-negative tonsillar and base of tongue cancer. PLOS ONE 2014, 9, e95624.

62. Tertipis, N.; Villabona, L.; Nordfors, C.; Nasman, A.; Ramqvist, T.; Vlastos, A.; Masucci, G.; Dalianis, T. Hla-a*02 in relation to outcome in human papillomavirus positive tonsillar and base of tongue cancer. Anticancer Res. 2014, 34, 2369-2375.

63. Nasman, A.; Romanitan, M.; Nordfors, C.; Grun, N.; Johansson, H.; Hammarstedt, L.; Marklund, L.; Munck-Wikland, E.; Dalianis, T.; Ramqvist, T. Tumor infiltrating CD8+ and Foxp3+ lymphocytes correlate to clinical outcome and human papillomavirus (HPV) status in tonsillar cancer. PLOS ONE 2012, 7, e38711.

64. Nordfors, C.; Grün, N.; Tertipis, N.; Ährlund-Richter, A.; Haeggblom, L.; Sivars, L.; Du, J.; Nyberg, T.; Marklund, L.; Munck-Wikland, E.; et al. CD8+ and CD4+ tumour infiltrating lymphocytes in relation to human papillomavirus status and clinical outcome in tonsillar and base of tongue squamous cell carcinoma. Eur. J. Cancer 2013, 49, 2522-2530. 
65. Hui, A.B.; Lin, A.; Xu, W.; Waldron, L.; Perez-Ordonez, B.; Weinreb, I.; Shi, W.; Bruce, J.; Huang, S.H.; O’Sullivan, B.; et al. Potentially prognostic mirnas in HPV-associated oropharyngeal carcinoma. Clin. Cancer Res. 2013, 19, 2154-2162.

66. Lajer, C.B.; Nielsen, F.C.; Friis-Hansen, L.; Norrild, B.; Borup, R.; Garnaes, E.; Rossing, M.; Specht, L.; Therkildsen, M.H.; Nauntofte, B.; et al. Different mirna signatures of oral and pharyngeal squamous cell carcinomas: A prospective translational study. Br. J. Cancer 2011, 104, 830-840.

67. Miller, J.F. Influence of thymectomy on tumor induction by polyoma virus in C57BL mice. Proc. Soc. Exp. Biol. Med. 1964, 116, 323-327.

68. Du, J.; Nordfors, C.; Ahrlund-Richter, A.; Sobkowiak, M.; Romanitan, M.; Nasman, A.; Andersson, S.; Ramqvist, T.; Dalianis, T. Prevalence of oral human papillomavirus infection among youth, Sweden. Emerg. Infect. Dis. 2012, 18, 1468-1471.

69. Kreimer, A.R.; Bhatia, R.K.; Messeguer, A.L.; Gonzalez, P.; Herrero, R.; Giuliano, A.R. Oral human papillomavirus in healthy individuals: A systematic review of the literature. Sex. Transm. Dis. 2010, 37, 386-391.

70. Rautava, J.; Syrjanen, S. Human papillomavirus infections in the oral mucosa. J. Am. Dent. Assoc. 2011, 142, 905-914.

71. Steinau, M.; Hariri, S.; Gillison, M.L.; Broutian, T.R.; Dunne, E.F.; Tong, Z.Y.; Markowitz, L.E.; Unger, E.R. Prevalence of cervical and oral human papillomavirus infections among US women. J. Infect. Dis. 2014, 209, 1739-1743.

72. Nordfors, C.; Vlastos, A.; Du, J.; Ahrlund-Richter, A.; Tertipis, N.; Grun, N.; Romanitan, M.; Haeggblom, L.; Roosaar, A.; Dahllof, G.; et al. Human papillomavirus prevalence is high in oral samples of patients with tonsillar and base of tongue cancer. Oral Oncol. 2014, 50, 491-497.

73. D’Souza, G.; Kreimer, A.R.; Viscidi, R.; Pawlita, M.; Fakhry, C.; Koch, W.M.; Westra, W.H.; Gillison, M.L. Case-control study of human papillomavirus and oropharyngeal cancer. N. Engl. J. Med. 2007, 356, 1944-1956.

74. Lang Kuhs, K.A.; Anantharaman, D.; Waterboer, T.; Johansson, M.; Brennan, P.; Michel, A.; Willhauck-Fleckenstein, M.; Purdue, M.P.; Holcatova, I.; Ahrens, W. Human papillomavirus 16 E6 antibodies in individuals without diagnosed cancer: A Pooled Analysis. Cancer Epidemiol. Biomark. Prev. 2015, doi:10.1158/1055-9965.EPI-14-1217.

75. Fakhry, C.; Rosenthal, B.T.; Clark, D.P.; Gillison, M.L. Associations between oral HPV16 infection and cytopathology: Evaluation of an oropharyngeal "pap-test equivalent" in high-risk populations. Cancer Prev. Res. 2011, 4, 1378-1384.

(C) 2015 by the authors; licensee MDPI, Basel, Switzerland. This article is an open access article distributed under the terms and conditions of the Creative Commons Attribution license (http://creativecommons.org/licenses/by/4.0/). 